fulfill the ASAS criteria for SpA, 21 patients underwent SIJ CT and 20 underwent SIJ MRI. Sacroiliitis was not visualized by CT in any patients and was visualized by $\mathrm{MRI}$ in 2 out of 20 patients (10\%). Sensitivity, specificity, positive and negative likelihood ratio of CT calculated with ASAS classification as golden standard were respectively estimated at $93.3 \%, 100 \%, 100 \%$ and $91.3 \%$. Youden index was estimated at 0.93 and $Q$ Yule coefficient at 1. Sensitivity, specificity, positive and negative likelihood ratio of MRI calculated with ASAS classification as golden standard were respectively estimated at $62.9 \%, 90 \%, 89.5 \%$ and $64.3 \%$. Youden index was estimated at 0.53 and $Q$ Yule coefficient at 0.88 .

Conclusion: In our study, the evaluation of sacroiliitis by CT, in comparison with MRI, has shown to be more sensitive and more specific. However, other factors should also be taken into account while comparing CT and MRI such as the high radiation exposure of CT scanning in the one hand and the cost and the restricted accessibility of MRI in the other hand.

Disclosure of Interests: None declared

DOI: 10.1136/annrheumdis-2019-eular.6460

\section{THU0385 COMPARISON OF CLINICAL AND DEMOGRAPHIC FEATURES OF JUVENILE SPONDYLOARTHRITIS BETWEEN ISRAELI AND US CHILDREN}

Merav Heshin-Bekenstein ${ }^{1}$, Naseem Ghantous ${ }^{2}$, Irit Tirosh ${ }^{2}$, Yonatan Butbul ${ }^{3}$, Liora Harel ${ }^{2}$, Yaniv Lakovsky ${ }^{2}$, Pamela Weiss ${ }^{4}$, Nadav Rappoport ${ }^{1}$, Kimberly Dequattro ${ }^{1}$, Emily von Scheven ${ }^{1}$, Lianne S. Gensler ${ }^{1}$, Amir Hendel ${ }^{2}$, John Mackenzie', Gil Amarilyo ${ }^{2}$. 'University of California San Francisco, San Francisco, United States of America; ${ }^{2}$ Tel Aviv University, Tel Aviv, Israel; ${ }^{3}$ Rambam Medical Center, Haifa, Israel; ${ }^{4}$ Children's Hospital of Philadelphia, Pennsylvania, United States of America

Background: Clinical observations among Israeli pediatric rheumatologists reveal that some of the clinical and demographic features of Israeli children diagnosed with Juvenile Spondyloarthritis (JSpA) are different as compared to the typical characteristics described in US studies.

Objectives: In this study, we compared clinical, laboratory and radiographic features to determine whether differences occur between the two populations of JSpA.

Methods: We performed a retrospective, cross-sectional, multicenter comparison of JSpA patients from 3 large Israeli pediatric rheumatology centers and a large US pediatric rheumatology center. Patients with a diagnosis of Juvenile Ankylosing Spondylitis (JAS) and/or Enthesitis-related Arthritis (ERA) were included. The demographic, clinical and imaging features of the subjects upon presentation were compared, including MRI of the sacroiliac joints. Inter Center Comparison (ICC) between the Israeli and US musculoskeletal radiologists was conducted.

Results: Overall 87 patients met the inclusion criteria (39 Israeli, 48 US). As compared to the US population, the Israeli population was less likely to be male $(56 \%$ vs. $75 \%, p=0.11)$, and more likely to be older at time of diagnosis (14.3 vs. 11.9 years, $\mathrm{p}<0.001)$. Upon presentation, axial symptoms (inflammatory back pain) and physical examination findings consistent with sacroilitis (SIJ tenderness, modified Schober test), were significantly more prevalent among Israeli patients $(59 \%$ vs. $35.4 \%, 48.7 \%$ vs. $16.7 \%$, and $41.2 \%$ vs. $21.5 \%$, respectively, all $p<0.05$ ), whereas peripheral arthritis and enthesitis were significantly more prevalent among the US patients $(43.6 \%$ vs. $91.7 \%$ and $7.7 \%$ vs. $39.6 \%$ in Israeli patients vs. US patients, $p<0.05$ ). For HLA-B27, $32 \%$ of the Israeli patients vs. $66.7 \%$ of the US patients were positive $(\mathrm{p}=0.007)$. In addition, of those who had imaging ( $N=30$ and $N=37$ for Israeli and US cohorts) $96.7 \%$ of the Israeli patients versus $29.7 \%$ of the US patients demonstrated positive MRI findings that were consistent with sacroilitis $(p<0.001$, overall $N=67$ ). An excellent level of agreement was observed between the Israeli and US musculoskeletal radiologists (kappa $=0.9$ ).

Conclusion: We found important distinctions between two populations with JSpA. Israeli children were more likely to present with axial disease, less likely to demonstrate HLA B27 carrier positivity, and more likely to demonstrate sacroilitis on MRI than US children, who more commonly presented with peripheral arthritis and enthesitis, HLA-B27 positivity and negative MRI findings. These unique findings of the Israeli JSpA population, also as compared to descriptions of JSpA patients in the medical literature, point to environmental and/or population specific factors that merit additional studies in order to unravel the differences in disease presentation between the two countries.

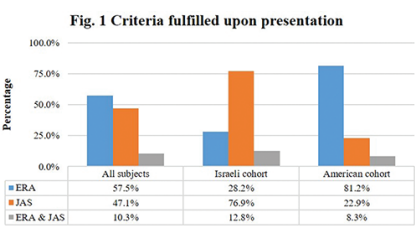

Abstract THU0385 - Figure 1

\section{REFERENCE:}

[1] Shirley M. L. Tse; Ronald M. Laxer. New advances in juvenile spondyloarthritis. Nature Reviews Rheumatology, 2012, Vol.8(5), p.269-279.

Disclosure of Interests: Merav Heshin-Bekenstein: None declared, Naseem Ghantous: None declared, Irit Tirosh: None declared, Yonatan Butbul: None declared, Liora Harel: None declared, Yaniv Lakovsky: None declared, Pamela Weiss Consultant for: Dr. Weiss has served as a con sultant for Lilly and Novartis., Nadav Rappoport: None declared, Kimberly DeQuattro: None declared, Emily von Scheven: None declared, Lianne S Gensler Grant/research support from: Abbvie, Amgen, UCB Pharma

Consultant for: Novartis, Lilly, Janssen, Amir Hendel: None declared, John MacKenzie: None declared, Gil Amarilyo: None declared DOI: 10.1136/annrheumdis-2019-eular.1357

\section{THU0386 CHILEAN AXIAL SPONDYLOARTHRITIS PATIENTSREPORT HIGH DISEASE BURDEN AND IMPAIRED WORK ACTIVITY - AN INTERNET SURVEY IN 472 PATIENTS}

Sebastian lbáñez ${ }^{1}$, Rianne van Bentum ${ }^{2}$, Omar Valenzuela ${ }^{1}$, Irene van der HorstBruinsma ${ }^{2} .{ }^{1}$ Universidad del Desarrollo - Clínica Alemana Medicine Faculty, Rheumatology, Santiago, Chile; ${ }^{2}$ Amsterdam Rheumatology and immunology Center, Amsterdam UMC, VUmc, Amsterdam, Netherlands

Background: Axial spondyloarthritis (axSpA) can be associated with significant burden and impaired work activity. In Chile, several barriers impede adequate treatment, such as insufficient access to specialists and biological treatment. Furthermore, there is an important lack of insight into the local situation. This hampers the development of adequate national treatment standards and financial support.

Objectives: 1. To evaluate the disease burden, quality of life and work participation in Chilean axSpA patients. 2. To assess gender differences in disease burden and 3) compare patients with and without biologics.

Methods: A cross sectional online survey among Chilean SpA patients, recruiting via the internet website and associated social media of the Chilean SpA Patient Foundation ("Espondilitis Chile"). The survey was written in Spanish and requested information, mostly via multiple choice options, on gender, age, disease characteristics (diagnosis, disease duration, treatment), disease burden (BASDAI and BASFI), quality of life (ASAS Health Index) and work participation (WPAI). Only axSpA patients were included for further analyses. The association between BASDAI, quality of life or work participation (presenteeism, absenteeism) and subgroups (gender, biologics) was assessed through univariable regression and subsequently multivariable regression analyses, correcting for age, disease duration and concomitant treatment (NSAIDs, DMARDs, opiates).

Results: Between July and October 2018, 625 patients completed the website survey, of whom 472 reported a diagnosis with axSpA $(91 \%$ radiographic axSpA, 37\% male, mean age 42 years, $83 \%$ BASDAI $\geq 4$, table 1). Twenty percent used a biological and patients with biologics were more likely to have a paid job $(p=0.01)$ and had significantly lower BASDAI, BASFI, ASAS $\mathrm{HI}$ and risk of absenteeism. In multivariable analyses, biologics remained significantly associated with a lower BASDAI. Interestingly, biologics were used significantly more often in male patients compared to females $(26 \%$ versus $16 \%, p<0.01$ ), while BASDAI, ASAS $\mathrm{HI}$ and chance of absenteeism and presenteeism were significantly higher in female patients (table 1). After correction for treatment, the gender difference in BASDAl, absenteeism and presenteeism was not significant anymore.

Conclusion: The results of the web survey demonstrate a high level of disease burden and work impairment in Chilean axSpA patients. The use of biologics is low, although its use is independently associated with having a lower disease activity. Women used significantly less biologics despite reporting a worse disease state (BASDAI, ASAS HI) and greater work disability, suggesting inequality in access to treatment. 
Abstract THU0386 - Table 1. Patient characteristics of Chilean axSpA patients ( $n=472$ ).

\begin{tabular}{|c|c|c|c|c|c|c|c|}
\hline & $\begin{array}{c}\text { Overall } \\
(\mathrm{n}= \\
472)\end{array}$ & $\begin{array}{l}\text { Men } \\
(\mathrm{n}= \\
173)\end{array}$ & $\begin{array}{l}\text { Women } \\
\qquad \begin{array}{c}(n= \\
299)\end{array}\end{array}$ & $p=$ & $\begin{array}{c}\text { Biologics } \\
(n=92)\end{array}$ & $\begin{array}{c}\text { No } \\
\text { Biologics } \\
(n=372)\end{array}$ & $\mathrm{p}=$ \\
\hline Gender, men & $173(37)$ & & & & $45(49)$ & $124(33)$ & $<.01$ \\
\hline Age, yrs & $42 \pm 10$ & $43 \pm 11$ & $41 \pm 9$ & .02 & $41 \pm 9$ & $41 \pm 10$ & ns \\
\hline $\begin{array}{l}\text { Disease duration, } \\
\text { yrs }\end{array}$ & $13 \pm 10$ & $13 \pm 9$ & $15 \pm 12$ & .02 & & & \\
\hline HLA-B27 positive & $232(49)$ & $110(77)$ & $121(52$ & $<.01$ & $47(57)$ & $180(61)$ & ns \\
\hline \multicolumn{8}{|l|}{ Current treatment } \\
\hline DMARD & $261(55)$ & $88(51)$ & $173(59)$ & ns & $41(46)$ & 217 (59) & .02 \\
\hline NSAIDs & $370(78)$ & $126(73)$ & 244 (82) & .02 & $59(65)$ & 305 (82) & $<.01$ \\
\hline BASDAI & $6.1 \pm 2.1$ & $5.8 \pm 2.3$ & $\begin{array}{c}6.3 \\
\pm 2.0)\end{array}$ & .03 & $5.2 \pm 2.2$ & $6.3 \pm 2.1$ & $<.01$ \\
\hline BASFI & $5 \pm 3$ & $5.1 \pm 2.8$ & $\begin{array}{c}5.4 \\
\pm 2.4)\end{array}$ & ns & $4.7 \pm 2.4$ & $5.5 \pm 2.6$ & $<.01$ \\
\hline $\begin{array}{l}\text { ASAS Health } \\
\text { Index }\end{array}$ & $10 \pm 4$ & $9 \pm 4$ & $10 \pm 3$ & $<.01$ & $9 \pm 3$ & $10 \pm 4$ & ns \\
\hline Currently paid job & $304(64)$ & $69(75)$ & $228(61)$ & .01 & $131(76)$ & $172(58)$ & $<.01$ \\
\hline $\begin{array}{l}\text { Absenteeism, } \\
\text { patients }\end{array}$ & $125(41)$ & $21(30)$ & $101(44)$ & .04 & $28(31)$ & $66(48)$ & $<.01$ \\
\hline $\begin{array}{l}\text { Presenteeism, } \\
\text { patients }\end{array}$ & $202(81)$ & $46(79)$ & $151(83)$ & ns & $81(75)$ & $120(88)$ & $<.01$ \\
\hline
\end{tabular}

Legend: Values are reported as numbers (\%) or mean ( \pm standard deviation, SD).

Acknowledgement: This study was conducted with help of the Chilean spondyloarthritis patient foundation "Espondilitis Chile".

Disclosure of Interests: Sebastian Ibáñez Consultant for: Novartis, Paid instructor for: Bristol Myers Squibb, Speakers bureau: Abbvie, Rianne van Bentum: None declared, Omar Valenzuela Consultant for: Novartis, Paid instructor for: Bristol Myers Squibb, Speakers bureau: Abbvie, Irene van der Horst-Bruinsma Grant/research support from: MSD, Pfizer, AbbVie, Consultant for: Abbvie, UCB, MSD, Novartis, Speakers bureau: BMS, AbbVie, Pfizer, MSD

DOI: 10.1136/annrheumdis-2019-eular.849

\section{THU0387 ENTEROPATHIC ARTHRITIS PATIENTS UNDER BDMARD TREATMENTS HAD FREQUENTLY RADIOGRAPHIC SACROILIITIS: HUR-BIO REAL LIFE RESULTS}

Gözde Kübra Yardımcı, Bayram Farisoğulları, Alper Sarı, Levent Kılıç, Berkan Armagan, Emre Bilgin, Ertuğrul Çağrı Bölek, Omer Karadag, Ali Akdoğan, Sule Apras Bilgen, Sedat Kiraz, Ali İhsan Ertenli, Umut Kalyoncu. Hacettepe University Medical School Internal Medicine, Rheumatology, Ankara, Turkey

Background: Enteropathic spondyloarthritis (eSpA) is one of the diseases in the Spondyloarthritis (SpA) spectrum and occurs in patients with inflammatory bowel disease (IBD). Sacroiliitis is frequently found in patients with IBD and can be overlooked because of focusing on IBD.

Objectives: Aim of this study is to evaluate the general features of eSpA and compare with psoriatic spondylitis (PsA), and ankylosing spondylitis (AS).

Methods: HUR-BIO (Hacettepe University Rheumatology Biologic Registry) is a prospective, single center database of biological treatments since 2005. eSpA patients were enrolled from HUR-BIO registry. Sacroiliitis was defined as modified New York criteria or based on ASAS magnetic resonance imaging criteria. Age and disease duration matched 128 ankylosing spondylitis and 96 psoriatic spondylitis patients were selected as a control group from HUR-BIO database. Demographic, clinical, laboratory, therapeutic data and imaging features were collected from this database: age, gender, age at disease onset, disease duration, type of IBD. Baseline disease activity before the first biologic therapy use was assessed with BASDAI, BASFI, VAS-patient global assessment, ESR and CRP.

Results: HUR-BIO SpA registry included $2576 \mathrm{SpA}$ patients, and 90 (3.5\%) patients had enteropathic arthritis (EA). Sixty four of 90 (71.1\%) patients had sacroiliitis according to modified NY criteria, and these patients were included in the study. Of the 64 patients with eSpA, IBD type was ulcerative colitis (UC) in 34 (53\%) patients, Crohn's disease (CD) in $30(47 \%)$ patients. For eSpA patients, initial biological DMARDs were infliximab in $26(40.6 \%)$, adalimumab in $23(35.9 \%)$, etanercept in $10(15.6 \%)$, golimumab in $4(6.3 \%)$, and certolizumab in 1 patient $(1.6 \%)$ The proportion of bDMARDs were similar with control group. Baseline disease activity were similar between eSpA and control group. However, baseline ESR levels were higher in eSpA than AS $(p=0.037)$ and psoriatic spondylitis $(p=0.001)$, as well. Baseline demographic and clinical features were summarized in Table 1.

Conclusion: Enteropathic spondyloarthrtis was present only a small part of all SpA patients. Sex, SpA family history, and uveitis were different from other SpA subgroups. Disease activities were similar with other spondyloarthritis, but particularly ESR level was higher in eSpA probably due to bowel disease activity. Sacroiliac and spine involvement seems to be the main reason for starting bDMARD in IBD patients, rather than peripheral arthritis.

Abstract THU0387 - Table 1. Baseline demographic features and disease activity in enteropathic spondylitis, ankylosing spondylitis and psoriatic spondylitis

\begin{tabular}{lcccc}
\hline & $\begin{array}{c}\text { Enteropathic } \\
\text { spondylitis } \\
(\mathbf{n}=64)\end{array}$ & $\begin{array}{c}\text { Ankylosing } \\
\text { spondylitis } \\
(\mathbf{n}=128)\end{array}$ & $\begin{array}{c}\text { Psoriatic } \\
\text { spondylitis } \\
(\mathbf{n}=92)\end{array}$ & $\begin{array}{c}\mathbf{P} \\
\text { value }\end{array}$ \\
\hline Female, $\mathbf{n}$ (\%) & $30(46.9)$ & $50(39)$ & $57(62)$ & $0.004^{*}$ \\
Age, years & $45.0 \pm 12$ & $45.3 \pm 10.6$ & $41.8 \pm 12.2$ & 0.163 \\
Age at diagnosis, years & $35.6 \pm 11$ & $34.8 \pm 10.5$ & $34.1 \pm 11.6$ & 0.763 \\
Disease duration, years & $9.17 \pm 6.9$ & $10.5 \pm 5.4$ & $7.7 \pm 6.9$ & $0.021^{*}$ \\
SpA family history, $\mathbf{n}$ (\%) & $15(23.4)$ & $15(11.7)$ & $31(33)$ & $0.000^{*}$ \\
$\begin{array}{l}\text { Uveitis, } \mathbf{n} \text { (\%) } \\
\text { HLA-B27 } \mathbf{n} \text { (\%) }\end{array}$ & $4(6.3)$ & $28(21)$ & $2(2.1)$ & $0.000^{*}$ \\
$\begin{array}{l}\text { Syndesmophyte } \\
\text { Switching between }\end{array}$ & $11(40.7)$ & $31(59.6)$ & $13(39.4)$ & 0.117 \\
biological drugs, $\mathbf{n}(\%)$ & $21(43.8)$ & $45(35.2)$ & $15(30)$ & 0.355 \\
$\begin{array}{l}\text { Baseline BASDAI } \\
\text { Baseline BASFI }\end{array}$ & $31(48.4)$ & $46(35.9)$ & $36(39.1)$ & 0.246 \\
$\begin{array}{l}\text { Baseline ESR mm/hr } \\
\text { (min-max) }\end{array}$ & $5.7 \pm 2.1$ & $5.4 \pm 1.7$ & $5.8 \pm 1.8$ & 0.271 \\
$\begin{array}{l}\text { Baseline CRP mg/dL } \\
\text { (min-max) }\end{array}$ & $1.6(0-8.6)$ & $3.5(0-9.8)$ & $4.1(0-8.7)$ & 0.577 \\
$\begin{array}{l}\text { Baseline patient global } \\
\text { assessment VAS (min- }\end{array}$ & $60(20-140)$ & $22(2-140)$ & $18(2-95)$ & $0.007^{*}$ \\
max) & & & & \\
\hline
\end{tabular}

Data were given as mean (standard deviation) or median (min-max)

HLAB27 were assessed in 27 eSpA, 52 AS and 33 PSA patients.

Disclosure of Interests: Gözde Kübra Yardımcı: None declared, Bayram Farisoğulları: None declared, Alper Sarı: None declared, Levent Kılıç: None declared, Berkan Armagan: None declared, Emre Bilgin: None declared, Ertuğrul Çağrı Bölek: None declared, Omer Karadag: None declared, Ali Akdoğan: None declared, Şule Apraş Bilgen: None declared, Sedat Kiraz: None declared, Ali İhsan Ertenli: None declared, Umut Kalyoncu Grant/research support from: MSD, Roche, UCB, Novartis and Pfizer, Consultant for: MSD, Abbvie, Roche, UCB, Novartis, Pfizer and Abdi Ibrahim, Speakers bureau: MSD, Abbvie, Roche, UCB, Novartis, Pfizer and Abdi Ibrahim

DOI: 10.1136/annrheumdis-2019-eular.5688

\section{THU0388 CLINICALLY RELEVANT DEFICITS IN PERFORMANCE TESTS IN PATIENTS WITH AXIAL SPONDYLOARTHRITIS (AXSPA) - MORE THAN COLLECTING QUESTIONNAIRES NEEDS TO BE DONE}

Uta Kiltz $^{1,2}$, Eerik Ahomaa ${ }^{1,2}$, Björn Bühring ${ }^{1,2}$, Xenofon Baraliakos ${ }^{1,2}$, Juergen Braun ${ }^{1,2} .{ }^{1}$ Rheumazentrum Ruhrgebiet, Herne, Germany, ${ }^{2}$ RuhrUniversity, Bochum, Germany

Background: Physical function in axial spondyloarthritis (axSpA) usually assessed by the BASFI questionnaire is an established core domain of that disease. There is evidence that self-reported physical function is not equivalent with the actual performance of patients. Physical performance can be assessed as a single task such as grip strength or single stance, or as a generic compound measure such as the short physical performance battery test (SPPB). SPPB comprises a chair rising test, balance test and gait speed.

Objectives: To investigate which performance tests are most frequently impaired in patients with axSpA.

Methods: Consecutive axSpA patients presenting to our tertiary hospital underwent a standardized assessment including patient and disease characteristics, patient-reported outcomes (ASDAS, BASFI, BASMI, ASAS Health Index (ASAS HI), PHQ-9) and performance tests (SPPB, grip strength and single stance). Structural damage was assessed by mSASSS. Validated cut-offs were used for SPPB, chair rise test, grip strength and gait speed. Impairment of performance tests as well as discrimination between subgroups was analysed.

Results: A total of 200 patients (r-axSpA 65.5\%, nr-axSpA 34.5\%) were included: $69 \%$ males, $44.3 \pm 12.5$ years of age, mean symptom duration 